\title{
A CONSCIÊNCIA METALINGÜIISTICA PRAGMÁTICA E SUA RELAÇÃO COM A PRODUÇÃO ESCRITA
}

\author{
THE PRAGMATIC METALINGUISTIC AWARENESS AND ITS \\ RELATION WITH THE PRODUCTION OF NARRATIVE TEXTS
}

\author{
FLÁVIA PINHEIRO DELLA GIUSTINA \\ Universidade Católica de Brasília \\ flaviagiustina@terra.com.br \\ Brasil.
}

TÂNIA MARIA DE FREITAS ROSSI

Universidade Católica de Brasília

taniamrossi@gmail.com

Brasil.

\section{RESUMO}

Este estudo investigou a consciência metalingüística pragmática e sua relação com a produção de textos narrativos de alunos de $5^{\mathrm{a}}$ série do Ensino Fundamental. $\mathrm{O}$ trabalho foi realizado com dois grupos de diferentes níveis de consciência metalingüística fonológica para verificar como os conhecimentos sistematizados dos conteúdos e conceitos científicos apreendidos ao longo das séries iniciais são organizados e estruturados para produzir textos escritos. Os relatos verbais possibilitaram compreender o intuito discursivo-social das crianças em suas escolhas de palavras, revelando os caminhos percorridos pelo pensamento até a sua materialização -a escrita. Os resultados obtidos mostram que o grau de consciência metalingüística está intrinsecamente relacionado com a representação real ou imaginária do outro-leitor, o qual influencia toda produção escrita.

Palavras chave: Desenvolvimento metalingüístico, consciência fonológica, consciência pragmática.

\section{ABSTRACT}

This study investigated the pragmatic metalinguistic awareness and its relation to narrative text production by fifth-graders. The research was carried out with two distinct groups, in which students were divided by their levels of phonological awareness. The main objective was to verify how systematic knowledge of scientific subjects and concepts learned during Early Childhood Education and Elementary School, are organized and structured to produce written material. The use of verbal stories allowed the understanding of the children's social intention through their choices of words, revealing the steps covered from its mental concept until its materialization -writing. The results show that the 
level of metalinguistic awareness is connected to the other-reader's representation, real or imaginary, which will affect all written work.

Keywords: Metalinguistic development, phonological awareness, pragmatic awareness.

Recibido: 23-05-2008. Aceptado: 26-08-2008

\section{INTRODUÇÃO}

$\mathrm{O}$

objetivo deste estudo foi o de investigar o nível de consciência metalingüística pragmática nas produções escritas de alunos de 5 a série do Ensino Fundamental para verificar a maneira como os sentidos e os significados são produzidos por estes alunos e o nível de reflexividade acerca de suas produçóes. Procurou-se apreender a forma como os alunos, em um determinado contexto, desenvolvem esta função, como articulam seus conhecimentos cotidianos e científicos.

Sob o aspecto do contexto social, a consciência metalingüística pragmática surge e se desenvolve, definindo-se como um "produto" do uso da linguagem no contexto interacional, e que também proporciona um outro desenvolvimento, o da cognição. Por intermédio da linguagem, a singularidade do sujeito é revelada, propiciando sua constituição, o despertar da consciência e o conhecimento de mundo. Então, consciência e conhecimento, portanto, são "produtos" dessa relação com o uso da linguagem estabelecida no contexto social com o outro. Há uma preocupação importante dos sistemas de ensino, de um modo geral, com as habilidades que os estudantes desenvolvem quando, no processo de escolarização, aprendem a ler e a escrever, ou seja, a utilizar a língua, uma expressão particular da linguagem.

Assim é que o Ministério da Educação, talvez por questões práticas, tem avaliado as habilidades dos alunos brasileiros em relação à leitura, deixando de lado a escrita. $\mathrm{O}$ órgão divulga periodicamente os resultados do Sistema Nacional de Avaliação Básica (SAEB), realizado em parceria com os estados da Federação, através do Instituto Nacional de Estudos e Pesquisas (INEP). As últimas publicações referem-se a dados coletados em novembro de 2003 por meio de questionários e testes aplicados em estudantes de $4^{\mathrm{a}}$ e $8^{\mathrm{a}}$ séries do Ensino Fundamental, do $3^{\mathrm{o}}$ ano do Ensino Médio, por professores e diretores das escolas amostradas (Ministério da Educação, 2004).

Os usos das habilidades reveladas no programa de avaliação mostraram a necessidade da construção de competências e o desenvolvimento de habilidades de leitura de textos de gêneros variados. São considerados "adequados" aqueles leitores que apresentam nível de compreensão de textos compatíveis com a série e demonstram habilidades de leitura consolidadas, pois estabelecem relação de causa e conseqüência em textos narrativos mais longos; reconhecem o efeito de 
sentido decorrente do uso da pontuação; distinguem efeitos de humor mais sutis; identificam a finalidade de um texto com base em pistas textuais mais elaboradas, depreendem relação de causa e conseqüência implícitas no texto, além de outros aspectos.

Os resultados indicaram que apenas $4,8 \%$ dos alunos que foram submetidos à avaliação no final da $4^{a}$ série, se enquadraram no estágio de habilidades considerado como "Adequado". Os 95,2\% restantes estavam distribuídos no estágio "Intermediário" (39,7\%), "Crítico" (36,7\%) e "Muito Crítico" (18,7\%). A análise feita pelo SAEB concluiu que nos estágios "Crítico" e "Muito Crítico", $55,4 \%$ dos estudantes desenvolveram habilidades elementares, tanto para a série quanto para a continuação dos estudos. São alunos que estariam acumulando déficits educacionais graves.

Como leitura e escrita são atividades interdependentes, os dados do SAEB mostraram a importância e a urgência de se levantar questões afeitas à leitura, mas também sobre as práticas de produções escritas na escola. Comumente, atribui-se a defasagem na escrita aos baixos níveis de leitura. Embora para avaliar a leitura também se observem os fatores desempenhados pelas habilidades metalingüísticas, o desenvolvimento da escrita em séries posteriores não tem sido focalizado para um entendimento do uso dessas habilidades. Além disso, as crianças assumem comportamentos lingüísticos específicos em função dos contextos sociais em que estão inseridas. Em função disso, é importante ampliar os estudos acerca da consciência dos alunos quanto às diferenças dos códigos lingüísticos: a fala e a escrita. Essas duas variedades no contexto escolar propiciam o despertar da consciência dos sujeitos com relação à adequação do uso da língua voltada para as diferenças, mas não é tão facilmente apreendida ou assimilada pelos alunos, acarretando dificuldades reais do processo de ensino-aprendizagem. É o que demonstram as pesquisas oficiais e, ao mesmo tempo, alicerça a necessidade de se estudar a construção da consciência metalingüística pragmática.

\section{CONTEXTO TEÓRICO}

Consciência metalingüística pragmática é definida por Crystal (1985) como a capacidade de reflexão do uso da linguagem, especialmente das escolhas acerca dos sentidos das palavras em intenção social, dos efeitos e do uso dessa linguagem no outro, o qual está envolvido no ato da comunicação. Tal nível de reflexão supõe uma criação de significados interpessoais surgidos no próprio contexto de comunicação. Trata-se de uma forma de consciência que pressupõe uma competência (como fazer), relacionada a uma habilidade comunicativa da linguagem (saber fazer), podendo-se dizer que o termo habilidade inclui conhecimento ou competência. A habilidade comunicativa de um indivíduo indica que ele é hábil, é um ser capaz 
de usar a língua de forma adequada aos contextos situacionais, ou seja, que é competente neste uso.

A consciência metalingüística pragmática consiste na reflexão dos aspectos da língua em uso, isto é, uma reflexão sobre o emprego dos recursos lingüísticos. A produção escrita implica a utilização desse tipo de consciência para estruturar os elementos lingüísticos (fonemas, grafemas, orações, parágrafos, etc.), organizar o pensamento, além de coordenar todos estes fatores com as exigências contextuais. Assim, a consciência metalingüística que é adquirida ao longo do processo de ensino, possibilita o desenvolvimento de outra habilidade metacognitiva, a consciência metalingüística pragmática, que auxilia o próprio sujeito no seu processo de aprender, de aprender a escrever.

Dessa maneira, estão envolvidas na reflexão metalingüística várias competências, tais como consciência fonológica (reflexão acerca dos sons), consciência da sintaxe (reflexão acerca das palavras), consciência semântica (reflexão acerca dos significados) e consciência pragmática (reflexão acerca do uso da língua em intenção social), e a falta de uma dessas consciências compromete todas as aprendizagens relativas a ler e escrever (Golbert, 1988). A capacidade ou consciência metalingüística é um resultado dessas aprendizagens explícitas, ou seja, de natureza escolar. As tarefas que enfocam a linguagem escrita requerem um nível mais abstrato, elaborado e controlado no seu uso que da linguagem oral. No entanto, o simples contato com a escrita não é suficiente para que a criança desenvolva uma consciência metalingüística. É importante que haja esforço por parte dela em utilizar a língua com controle intencional, requerido pela escrita. $\mathrm{O}$ motor dessa evolução é a intervenção (o ensino), pois a passagem de um estágio para outro é possibilitada pela compreensão dos códigos escritos (Gombert, 2003).

O termo competência neste estudo pretendeu afastar-se da definição clássica de Chomsky (1973), puramente lingüística, sobre o conhecimento da língua, das estruturas, das regras e do seu uso em situações concretas. Esse termo foi ampliado na abordagem funcional/nocional da língua surgida no final da década de $70 \mathrm{com}$ Hymes (1979). Este extrapola o conceito inicial de competência para além da preocupação com o uso da língua quanto à fonologia, sintaxe, léxico e semântica, incluindo a dimensão social da capacidade do uso, contrapondo à idéia primeira.

Somente na década de 90, o que até então se chamava de competência passa a ser entendido como conhecimento. O termo competência, por carregar uma grande bagagem semântica, torna-se compreendido como uma capacidade de utilizar o conhecimento da língua em sintonia com o contexto para criação e interpretação dos significados (Bachman, 1991). Para esse autor, ao utilizar conhecimentos específicos da língua, os indivíduos denotam competência lingüística e uso de estratégias metacognitivas.

A confusão gerada pela nomenclatura muitas vezes torna difícil a compreensão de cada termo utilizado pela literatura, exigindo um esforço de definição dos 
conceitos, de modo a evidenciar as abordagens e diferenças significativas entre eles, e estabelecer um relativo ponto de convergência que permita sua utilização. De qualquer maneira, a literatura mostra que há um conjunto significativo de pesquisas (Yavas, 1998; Spinillo e Simões, 2003; Jiménez e Venegas, 2004; Correa, 2004;) que indicam não apenas várias maneiras de conceber o conceito, como a diversidade de níveis apresentados por crianças nas habilidades metalingüísticas e o quanto tais habilidades são preditoras de um bom leitor. Contudo, a habilidade metalingüística pragmática como preditora para produção escrita aparece diluída nesses estudos.

Outras investigações sobre a aquisição e o desenvolvimento da leitura e da escrita nas séries iniciais que compreendem da alfabetização a $4^{\mathrm{a}}$ série do Ensino Fundamental (Martins, 1991; Bialystok, 1993; Rego, 1993, 1995; Maluf e Barrera, 1997; Rego e Buarque, 1997; Cielo, 1998; Gombert e Colé, 2000; Barrera e Maluf, 2003) revelam grande interesse em estudos acerca das habilidades metalingüísticas utilizadas na execução de tarefas lingüísticas, em situação de ensino formal. Concebem a língua como objeto de manipulação consciente, visando a atender às demandas contextuais de produção. Evidenciam que, para execução dessas tarefas, é necessário que se tenha um desenvolvimento de domínios ou de competências lingüísticas que integram características muito próprias e interrelacionadas, indicadoras de um conhecimento implícito e explícito das regras de uma língua.

Geraldi (1997) e Gombert (2003) esclarecem que, nos processos interacionais, habilidades precursoras das metalingüísticas já estão presentes em crianças a partir de dois ou três anos de idade. Essas habilidades precursoras, ou seja, epilingüísticas podem ser percebidas por intermédio de autocorreçōes durante a fala, contudo não ocorrem de maneira intencional por parte das crianças, tendo como suporte $o$ conhecimento explícito das regras da língua. O controle consciente das habilidades metalingüísticas aparece somente em situações de ensino da própria linguagem escrita, conforme já mencionado. Enquanto o comportamento metalingüístico está sob o controle consciente, o epilinguístico ainda não está.

O uso da consciência pragmática, como habilidade metalingüística utilizada na produção escrita é considerada por Bakhtin (1997[1929]) como aquela que aborda os significados explícitos e implícitos necessários à construção de novos significados dentro dos diversos contextos para melhor compreensão de enunciados. Para ele, cada uma das enunciaçôes tem sentido próprio, porque são produzidas em situações particulares. Assim, os sentidos aparecem no plano comunicativo, envolvem os outros sociais do diálogo e revelam uma compreensão verdadeira do que já foi enunciado. Já para Vygotsky (1991[1987]), a criança tem acesso à consciência metalingüística por meio dos conhecimentos científicos sistematizados no aprendizado escolar que se inter-relacionam com os conceitos cotidianos. Ao interagir na escola, ela transforma seu conhecimento de mundo, através da palavra, 
em conhecimento generalizante. $\mathrm{O}$ autor sustenta que as relações estruturais e funcionais das palavras no ciclo evolutivo ocorrem em estágios primitivo, intermediário e avançado, encontrando uma regularidade genética. Desse modo, no princípio, a palavra só tem função nominativa e, semanticamente, só referência objetiva. Em estágios posteriores, a significação se torna independente da nomeação e o significado independente da referência. É quando ocorre o desenvolvimento das habilidades metalingüísticas, momento em que os múltiplos significados das palavras permitirão escolhas dentro de um contexto.

O termo metaconsciência, segundo Vygotsky (1991[1987]), refere-se à tomada de consciência e a organização deliberada da experiência e do controle cognitivo. Parte da linguagem que é reguladora da metaconsciência tem natureza pessoal, apreendida pelo sujeito. Apresenta diferenças na sua constituição e funcionamento, sendo esta relatividade lingüística observada nas diferentes línguas, mas não diferindo na natureza desses processos.

Para Igoa (2003), os processos conscientes representados pela metacognição, são de grande importância para a aprendizagem ou desenvolvimento da escrita, e apresentam-se em duas funções: conhecimento metacognitivo e auto-regulação. $\mathrm{O}$ primeiro trata do conhecimento adquirido sobre o próprio pensamento e, o segundo, é a possibilidade de utilizar esse conhecimento para planejamento, monitoramento e avaliação de uma atividade. Este recurso possibilita melhor alcance nos resultados de aprendizagem e execução de tarefas.

A consciência metalingüística tem sido investigada em sua relação com a aprendizagem de leitura e escrita por vários estudiosos (Albuquerque, 1994; Albuquerque e Spinillo, 1997; Borges Dias, 2000; Cielo, 1998; Golbert, 1988; Gombert, 1992, 1993, 2003; Gombert e Colé, 2000; Colaço, 2001; Guimarães, 2003) voltada para a fonética, sintaxe, léxico, pragmática, e mais recentemente, a literatura tende a focalizar a consciência metalingüística textual.

Os autores Spinillo e Simões (2003) afirmam que a consciência metatextual ainda é pouco estudada quando comparada às demais habilidades metalingüísticas e foi Gombert (1992) um dos precursores em adotar o aspecto consciência metatextual dentro das habilidades metalingüísticas, como a unidade de análise do texto pautado na atenção deliberada e intencional dirigida para o texto e não para seu uso. Esta envolve apenas os aspectos intralingüísticos, relacionados ao próprio texto, enquanto a consciência metalingüística pragmática já engloba as relações dos aspectos intralingüísticos, relacionando também ao contexto em que foi gerado (Albuquerque, 1994).

Como essas experiências estão todas ligadas, de fato, percebe-se que a linguagem, pensamento e consciência se constituem ao longo do desenvolvimento humano e propiciam o conhecimento por meio das relaçóes com o outro e com o meio social, por meio da palavra. É através da palavra que o sujeito adquire ao longo do desenvolvimento uma reflexão generalizada da realidade. 
Tomando o texto como uma produção escrita, porta de entrada para o conhecimento, estão sempre presentes nele duas consciências, de dois sujeitos: de quem escreve e de quem lê. É nesse encontro dialógico que se dá a compreensão do que foi dito por escrito. De acordo com Bakhtin (1997[1929]), é preciso haver uma vontade consciente para estabelecer essa relação que não se dá a partir de uma compreensão puramente lingüística ou mecânica. A seleção dos recursos lingüísticos para composição dos enunciados nasce e se forma em interação, no elo da cadeia dos outros enunciados, em luta com o pensamento alheio, com objetivo de comunicação.

Ao tornar-se consciente do outro, é que o sujeito também se torna consciente de si mesmo. A presença do outro na interação, seja ele presente face a face, ou representado mentalmente, como no caso da linguagem escrita, é que propicia o desenvolvimento da consciência.

Dessa forma, pretendeu-se verificar como a consciência metalingüística pragmática interfere nas produções escritas, partindo da premissa de que é por intermédio da perspectiva dialógica e interacional surgida no ambiente escolar, que tal consciência se constitui e se desenvolve.

\section{MÉTODO}

\section{PARTICIPANTES}

Participaram da pesquisa dez alunos, não repetentes, com idade entre dez e onze anos, estudantes de uma escola particular no Plano Piloto, em Brasília, de nível socioeconômico considerado favorecido. Os participantes foram selecionados em uma turma de 28 alunos, com base na análise de produçôes escritas realizadas previamente. Dentre estas foram escolhidos dois grupos distintos, 5 com maior e 5 com menor nível de competência em escrita, tomando-se como critério as habilidades metalingüísticas relacionadas a erros ortográficos. Tal procedimento objetivava obter dados para comparar o nível de reflexividade dos dois grupos distintos.

\section{INSTRUMENTOS}

Três instrumentos foram utilizados para avaliar as produções escritas. O primeiro, Avaliação preliminar da consciência metalingüística fonológica quanto a erros ortográficos, foi utilizado para avaliar a produção escrita da turma como um todo por ser considerado por Carraher (1985), Cagliari (1997), Zorzi (1998) e por Guimarães (2003) como um facilitador na verificação do domínio lingüístico e por focalizar o desenvolvimento da competência lingüística na aprendizagem 
ortográfica para sucesso na leitura e escrita.

Para esses autores, as alterações ortográficas de uma produção escrita revelam o desenvolvimento da competência na aprendizagem da escrita, e identificam os diversos tipos de erros ortográficos produzidos durante a evolução dessa aprendizagem, os quais estariam relacionados com a consciência fonológica. As crianças ao ignorarem a sutileza ortográfica cometem erros de associação da forma escrita à estrutura fonológica. Em consonância com esses estudos partiuse do princípio de que a compreensão e o uso adequado do conhecimento mais sistematizado sobre determinadas correspondências ou não de letras e sons ativa um tipo de reflexão de seqüência de fonemas, da palavra inteira ou de partes dela o que permite identificar os diferentes níveis dessa consciência nos sujeitos. A competência lingüística dos 10 sujeitos foi verificada nos textos produzidos segundo a análise de erros ortográficos relacionados com a consciência fonológica, conforme prevê Guimarães (2003), a saber: transcrição da fala; omissão de letras em sílabas de estruturas complexas; acréscimo de letras; contaminação; ausência de nasalização; trocas surdas/sonoras; trocas de letras graficamente parecidas; inversão de letras e sílabas; erros por desconsiderar as regras contextuais; erros de segmentação; erros por desconhecimento de regras morfossintáticas; erros ligados ao desconhecimento da origem das palavras; e erros por generalização de regras.

O segundo instrumento foi elaborado e validado pela pesquisadora, apoiandose na teoria de Bakhtin e Gombert, e nos estudos de Cardoso (2000) para proceder a Avaliação da consciência metalingüística pragmática. Consideraram-se aspectos essenciais à construção de um texto com consciência: reflexão quanto ao contexto, uso, intenção e efeitos.

E o terceiro consistiu de um roteiro para realizar entrevistas de Explicitação, semi-estruturadas visando a melhor compreensão do pensamento que norteou as produções escritas e como forma de incitar a relação dialógica entre dois textos, duas consciências (de quem escreve, de quem lê), segundo Bakhtin (1997[1929]), ou seja, contexto, uso, intenção social e efeito no outro.

As escolhas das palavras e seus termos de intenção social foram, depois de identificadas, transcritas como relatos de explicitação.

\section{Procedimentos}

Para realizar a Avaliação preliminar da consciência metalingüística fonológica quanto a erros ortográficos ( $1^{a}$ tarefa) solicitou-se aos participantes que escrevessem um texto intitulado: eu sou assim, em sala de aula, como atividade de rotina da disciplina Língua Portuguesa.

Uma vez identificados os 5 participantes com maior e os 5 com menor nível de consciência fonológica, foi proposto a esse grupo que elaborasse produções escritas (PEs) em forma de narrativa ( $2^{a}$ tarefa). 
Os encontros da primeira e da segunda tarefa contaram com três etapas dirigidas aos sujeitos: motivação, preparação e produção escrita. Os participantes foram mobilizados para que escrevessem, contextualizando a situação de escrita. Relacionando com o que já haviam escrito no primeiro momento, na segunda tarefa eles contaram uma história, um fato marcante que teria lhes acontecido.

As produçôes escritas foram identificadas, numeradas e agrupadas de acordo com o nível de consciência fonológica relacionada aos erros ortográficos.

Em seguida, procederam-se as "entrevistas de explicitação" que envolviam diálogos individuais, nos quais a criança era convidada a falar sobre sua produção escrita, seu processo de criação, seu desejo de dizer algo ao outro, sua percepção da escrita, as exigências formais da escrita, a necessidade de revisar, etc. As entrevistas foram individuais, agendadas e gravadas em áudio, ocorrendo num espaço reservado da escola. Após, foram transcritas e analisadas de acordo com os critérios da consciência pragmática: reflexão do contexto, uso das palavras no texto, intenção, bem como os efeitos das palavras em intenção social.

A opção de verificar a consciência pragmática em grupos de diferentes níveis de consciência fonológica criou condiçôes para avaliar a relação entre estas duas categorias.

\section{RESULTADOS}

\section{1a Etapa - Tarefa para Análise da Consciência Metalingüistica Fonológica quanto a erros Ortográficos}

Os resultados foram obtidos a partir do número de falhas recorrentes em cada produção escrita (PE). Baseando-se nos critérios de análise de categorização dos erros ortográficos, todas as alteraçōes ortográficas apresentadas nas produçōes escritas foram marcadas, identificadas e somadas, individual e coletivamente, para melhor conhecer os diferentes níveis de consciência metalingüística dos alunos.

Os resultados obtidos indicaram: que, no total de 28 alunos, apenas 5 não obtiveram alteraçôes ortográficas em suas produções; 4 apresentaram 1 alteração; 1 aluno apresentou 2; 3 apresentaram 3 alteraçôes e 1 aluno apresentou 4.

Do total de pesquisados, 14 evidenciaram alterações ortográficas compreendidas entre 5 a 22 recorrências.

A maior incidência de alterações ortográficas foi quanto aos erros por desconsiderar as regras contextuais, cometidos por 16 alunos.

$\mathrm{O}$ segundo critério que obteve maior incidência dizia respeito à transcrição da fala, apresentado por 13 alunos.

Dentre os 28 alunos, 5 se destacaram por não apresentar nenhuma alteração 
ortográfica em suas produções, e 5 por apresentarem uma incidência maior dessas alterações na turma.

Com base nesses resultados, os alunos que mais se destacaram na análise das produçōes escritas, Assim, Lena, Cléa, Jane, Bia e Pedro apresentaram maior consciência metalingüística fonológica (Grupo I) e Marcos, João, Rui, Rosa e Luis $^{1}$ (Grupo II) com menor consciência.

\section{2a Etapa - Tarefa para Análise da Consciência Metalingüistica Pragmática}

Os resultados de nível de consciência metalingüística pragmática dos participantes escolhidos a partir da reflexividade da própria produção escrita são apresentados de acordo com os seguintes critérios de gradação: Ausente - quando o sujeito não percebe o aspecto a ser avaliado em sua produção escrita; Fraco - quando este ainda não está internalizado, mas o sujeito demonstra um início do processo consciente através da interação dialógica; Médio - o sujeito demonstra domínio do aspecto enquanto escreve, porém não revela uma compreensão do seu uso nas entrevistas de explicitação; Forte - quando o sujeito já apresenta o domínio deste aspecto, o faz presente no seu planeja e monitoramento durante a produção escrita, e consegue explicitar o seu uso nas entrevistas. A consciência dos sujeitos é apontada por essa graduação ao considerar o ato de consciência da palavra ligada ao contexto, uso, intenção e efeito surgidos durante a concepção de uma produção escrita, podendo ser observada no processo dialógico dos textos.

Importante observar que essa gradação revela uma variação nos níveis de desenvolvimento dessa competência, e as situações dialógicas proporcionadas pela prática reflexiva das produções escritas parecem responsáveis pela sua evolução, ao tomar como base as quatro categorias para produção textual (Contexto, Uso, Intenção Social, Efeitos).

\section{DISCUSSÃO}

Os resultados da consciência metalingüística fonológica quanto a erros ortográficos sugerem, de fato, a variedade de nível da competência lingüística dos sujeitos em relação à incidência das alterações ortográficas verificadas nas produções escritas quanto aos critérios de análise, conforme postulado por Guimarães (2003). Indicam que tais dificuldades dos alunos nas representações ortográficas de ordem fonológica se tornam um obstáculo para assimilação de regras contextuais mais complexas. Importante ressaltar que houve um maior número de incidência de

${ }^{1}$ Nomes fictícios. 
alterações porque os alunos desconsideraram as regras contextuais e transcreveram as palavras como pronunciadas na fala. Esse fenômeno aponta para a necessidade de contextualização da escrita na escola, pois seu uso apropriado quanto às representações ortográficas está em acordo com as regras contextuais geradoras das produções.

Tais resultados confirmaram que a evolução do domínio lingüístico, assim como da consciência metalingüística fonológica, não ocorre de forma tão estruturada e linear no processo de desenvolvimento (Correa, 2004). Na realidade, eles estão em acordo com as conclusões de Guimarães (2003), uma vez que revelam que crianças com maior dificuldade na aprendizagem da leitura e, principalmente da escrita, têm menos habilidade fonológica que as outras crianças. A contribuição da autora foi mostrar que grande parte das dificuldades de escrita dos alunos está relacionada com problemas de natureza fonológica. Então, a tomada de consciência e reflexividade do sujeito acerca das palavras ao longo desse desenvolvimento são incorporadas por meio da aprendizagem, através da mediação (Vygotsky, 1991). As situações interacionais ocorridas no espaço social, na escola, contribuem para a evolução da consciência do uso da língua.

Os resultados obtidos na análise da consciência metalingüística pragmática nos dois grupos indicaram que houve maior percepção do grupo I, dos aspectos levantados nas 4 categorias (contexto, uso, intenção social e efeitos); embora um sujeito do grupo II, de menor consciência metalingüística, Marcos, tenha se destacado por sua maior habilidade reflexiva, mesmo apresentando diferenças significativas quanto ao nível de consciência fonológica comparado com o grupo II.

O nível de reflexividade das produções revelou a percepção dos alunos acerca dos aspectos descritos e indicou os níveis de consciência pragmática, o que se apresentará a seguir considerando cada categoria separadamente.

\section{Categoria 1 - contexto}

Segundo Bakhtin (1997[1929]), a consciência entendida como resultado do processo interacional pode ser revelada através da dialogia dos textos. $\mathrm{O}$ texto, por ser reticente, pressupõe um leitor que o critique, que o complete. Portanto, a consciência surge e se desenvolve a partir dos textos, de quem escreve e de quem lê, num encontro dialógico. Os aspectos determinantes das narrativas produzidas são dirigidos ao outro real e imaginário. Os desígnios desses textos marcam a situação social, as fronteiras do querer- dizer de cada participante. A presença do outro na interação possibilita o despertar da consciência, delimitando sentidos. Essa preocupação com o outro deveria estar presente no sujeito consciente desse uso, visto que a interpretação pluralística dos enunciados transcende aspectos puramente lingüísticos. Textos escritos geram outros textos por parte de quem leu. 
De fato, os resultados demonstraram que a atitude de quem escreve é a de esperar respostas do outro, exigindo que se trabalhe de forma consciente com as palavras, e os sentidos indesejáveis sejam inibidos.

Para Vygotsky (1991 [1987]), a percepção dos sentidos das palavras no contexto indica o motivo gerador dessas escolhas. Para ele, ao entender o motivo que conduz o sujeito a escrever uma ou outra palavra, compreende-se seu pensamento. Os resultados mostraram que os subtextos presentes por trás das palavras revelaram os vários pensamentos, os caminhos que levaram o sujeito a escolhê-las. Aquilo que desejava inibir, não contar, ressaltar sentidos foram marcados pelas palavras e durante as entrevistas de explicitação foi verificado essa tomada de consciência para tais escolhas. O grau de consciência em relação ao acabamento dos enunciados revelou também o grau de orientação social: como o sujeito percebia o outro, como atendia aos seus pedidos, como desejava compartilhar suas idéias, os fatos vividos, sua visão de mundo.

Importante ressaltar que ainda nessa categoria-contexto, muitas vozes perpassaram o texto no momento da concepção, conforme Bakhtin (1997[1929]). A apropriação dessas vozes e seu uso consciente foram devidamente relacionados com o contexto e determinaram escolhas de palavras. O que foi ouvido e pôde ajudar na construção do texto para delimitar sentidos foi utilizado no momento escolha das palavras e poderiam ser percebido no momento da interação, como sendo uma modalidade de despertamento da consciência do que se fala. $\mathrm{O}$ fato de perceber quais eram as falas dos outros e de utilizá-las na construção do texto para atender aos desígnios iniciais da produção indicou um uso consciente desse recurso. As palavras do outro foram introduzidas com expressividade, com tom valorativo, e determinaram na narrativa a marca da situação contextual de um tempo e espaço, cabível para sua construção.

O grau de consciência, então, foi verificado nos sujeitos quando consideraram ou não outras possibilidades de leitura de seus textos por parte do outro. No texto, as fronteiras de expressão são "pistas" percebidas pelo outro através do contexto, isto é, dado à situação transversal que sugere a escrita de possuir expressões duplas: a de quem escreve e a do contexto em que as palavras se apóiam.

Os relatos de explicitação do grupo I, como exemplo, no aspecto 1.1Preocupação com o outro real, revelaram consciência na definição do conteúdo a ser contado através da escrita, mostrando que a presença do outro real se fez evidente e determinante do texto produzido (Bakhtin, 1997[1929]). O fato escolhido sugere um desejo de mostrar o que era importante, revelado nos turnos selecionados da explicitação feita por Lena: 


\section{P: O que você pretendia me contar quando você escreveu?}

Lena: É que essa história conta que... quando eu era bebê minha mãe ficou noiva de um moço... que eu chamava de pai, ... que eu ainda não conhecia meu pai... ai depois... ai depois eles se separaram... ai no meu aniversário de 10 anos eles juntaram de novo... aí... eu fiquei feliz e ai depois eles se separaram de novo.

Assim como o grupo II, para Rui, Rosa e Marcos, a preocupação com o outro real também foi marcada.

Rui: Eu pretendia contar que eu fiz uma coisa errada, e queria confessar, é... mas só que... eu tinha caído naquele dia, ai por isso que eu fui internado. Eu queria que você soubesse que...que eu caí.

Rosa: Ah... ah, pra você ver... que esse dia marcou para mim, né, pra você ver que eu gosto de festa, gosto de piscina, gosto de viajar, eu gosto... gosto de ir para Caldas Novas.

Marcos: Um momento bom, que eu tive na minha vida, que foi marcante, porque eu nunca mais vou esquecer!

Foram constatadas diferenças significativas quanto ao nível de consciência pragmática dos dois grupos analisados em relação ao contexto da produção. No grupo I, todos os sujeitos passaram a idéia de uma forte preocupação com o outro real, produzindo textos que atenderam aos objetivos propostos. A variação no grupo II indica que os sujeitos com menores níveis de consciência metalingüística fonológica apresentaram oscilações no nível da consciência pragmática, pois não mostraram uma regularidade no domínio desses recursos necessários à construção de um texto marcadas pelas relaçôes sociais, possivelmente pela influência do meio em que está inserido. Marcos destacou-se no grupo II por ter conseguido explicitar seu pensamento durante a escrita, indo ao encontro do seu planejamento inicial.

\section{Categoria 2 - uso}

Esta categoria pretendeu verificar a forma como os sujeitos utilizaram a língua, as palavras para produzir os textos, considerando-se a construção, estrutura, forma e hierarquização de seu conteúdo. Para Vygotsky (1991[1987]), a intenção social é a base de todo o processo de conscientização, condição necessária para inserção do sujeito na cultura. Esse fator é de fundamental importância para o ato de escrever, e auxilia no desenvolvimento da prática da escrita uma vez que conteúdo, estrutura e complexidade das produçóes estão relacionados com o desenvolvimento do pensamento, com as habilidades metacognitivas. A intenção social identificada nas narrativas como modelo cultural do texto produzido, com sua estrutura e formas bem definidas, permitiu observar a internalização deste gênero textual por 
parte dos participantes, além de possibilitar a expressão de suas experiências, como explicaram, de forma pertinente, o esquema narrativo quanto a tempo e espaço.

Lena: Quando eu era bebê, quando eu tinha dez anos, e hoje.

Cléa: O começo, o meio e o fim.

Bia: Hum... seria... o começo né, quando eu estava indo para o colégio, foi o primeiro ano que comecei a estudar, e...falei depois que quando estudei em outro colégio, e que eu aprendi a lição.

Jane: Bom, as partes seriam: a primeira parte seria quando eu estava me arrumando, eu estava muito ansiosa, eu acordei até sozinha, porque geralmente eu não acordo sozinha para ir para escola, acordei sozinha, estava ansiosa, essa sim foi a primeira parte. E a segunda parte foi que ... que eu cheguei na escola ás 6 horas da manhã, a gente atrasou um pouco, mas ai a gente seguiu a viagem e chegou lá tranqüilo. E a terceira parte, foi a parte que a gente divertiu lá e aí depois voltou para casa.

No grupo II, Rosa realizou a tarefa com as partes estruturadas de uma narrativa, mas não conseguiu explicar a sucessão, ainda que a tenha relacionado as partes entre si.

Rosa: As partes mais importantes... não sei. Ah... eu ia colocar as coisas mais importantes, é que às vezes assim.... eu coloquei tudo que aconteceu, só que tá assim, é tem muita coisa assim que não era importante, mas eu coloquei. Uma é lá em casa que estava sem graça, tava muito ruim, a segunda é que eu conhecia uma amiga, que a gente foi e deu certo e na terceira é que a gente foi embora.

$\mathrm{Na}$ identificação da estrutura textual, Luiz e Marcos demonstraram uma fraca percepção da estrutura, pois, apesar de realizarem a tarefa de forma adequada, não identificaram coerentemente com o que haviam escrito, de maneira consciente:

Luiz: Eu sempre divido na parte escrita e na parte concentrada. Aqui nesse texto o que eu fiz foi só explicar.

Marcos: Dividi em parágrafo primeiro, essa, depois essa... A primeira parte fala do que eu gostava, do que gosto e do que eu estava fazendo. A segunda parte fala do que eu comecei a fazer coisa do que gostava realmente. A terceira fala das conquistas e da felicidade que eu tive fazendo a coisa que eu sempre quis fazer. A última fala que todos os momentos, foram inesqueciveis para mim.

Rui e João não conseguiram identificar a estrutura do texto.

Rui: Ué! É... não sei.

João: Não. 
Mas Rui revelou consciência de alguns aspectos relativos à forma de uma narrativa, ao ter internalizado alguns conceitos científicos (narrador e personagem).

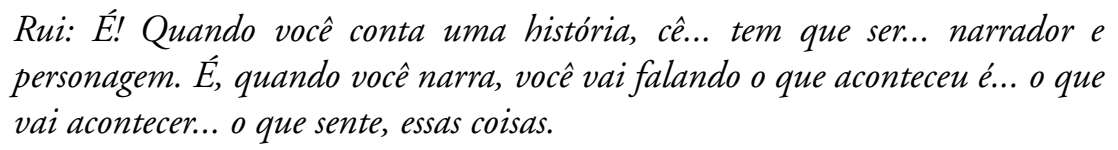

Rui: É! Quando você conta uma história, cê... tem que ser... narrador e personagem. É, quando você narra, você vai falando o que aconteceu é... o que vai acontecer... o que sente, essas coisas.

É, portanto, possível que a explicitação de conceitos e da estrutura relacionados à construção de um texto pode facilitar a realização desta tarefa.

Importante ressaltar que no grupo II ocorreram oscilaçôes significativas quanto ao domínio de recursos lingüísticos quanto ao uso da linguagem. O grupo I também apresentou menor variação na percepção dessa categoria, e demonstrou uma maior consciência das palavras utilizadas que atenderam ao planejamento preliminar de construção das narrativas. A interlocução, dialogia dos textos segundo Bakhtin, foi o que possibilitou momentos de reflexão quanto à hierarquização das idéias no grupo I e gerou dúvidas e insegurança no grupo II.

\section{Categoria 3 - intenção social}

Segundo Vygotsky (1991[1987]), para compreender as palavras de outrem é preciso que se compreenda, também, seus pensamentos e motivações, o que, entretanto, não assegura uma totalidade de entendimento, pois há um conjunto de motivos paralelos que orbitam a produção escrita. Para Bakhtin (1997[1929]), intenção social dos motivos paralelos do discurso é percebida nos atos de enunciação. As palavras foram escolhidas buscando atender aos desígnios do texto de intencionalidade discursiva e trouxeram marcas da subjetividade. $\mathrm{O}$ texto refletiu a consciência da criança em sua escolha ao explicitar o motivo que a levou escrever uma ou outra palavra. Observou-se que a explicitação desse motivo não se deu em uma única palavra, reforçando as idéias de Vygotsky que os significados das palavras evoluem ao longo do desenvolvimento, revelando uma modificação do pensamento quanto à complexidade, ao longo das tentativas de explicitação.

No encontro dialógico da escrita pode-se notar a vontade consciente de estabelecer uma comunicação. $\mathrm{O}$ desejo de comunicar é uma intenção e se torna presente durante toda a escritura. Escrever é uma atividade autoreguladora do pensamento (Gombert, 1992, 1993, 2000, 2003), e o processo consciente de escrever traz o compromisso do entendimento do outro. Através da escolha das palavras, os enunciados tornam-se fenômenos complexos construídos com esse objetivo e refletidos a partir de outros enunciados que são sempre respostas esperadas na cadeia de enunciados.

O grupo I, Lena, Cléa, Jane, Bia e Pedro apresentaram os enunciados com expressividade e juízo de valor, revelando que os sentidos foram construídos 
dentro do contexto da produção, com adequação da linguagem quanto ao uso, em consonância com os desígnios de cada texto Bakhtin (1997[1929]). Ao considerar o outro real as palavras escolhidas refletiram a consciência dos sujeitos quanto à apropriação dos signos e a compreensão conceitual dentro do contexto situacional de produção. Como se pode perceber nos turnos que se seguem:

\section{P: Porque você escolheu, é ... contar, utilizar esta palavra aqui?}

P: Moreno daria para ser substituida por outra?. S: Não, porque ele é moreno mesmo, ele não é negro! P: Trauma, por que você escolheu esta palavrinha aqui, e por qual ela poderia ser substituida? Bia: É ... escolhi essa porque foi realmente o que aconteceu, que eu tive um trauma, e eu acho é.... que poderia ser substituida pela palavra é... uma coisa que você tem medo, que você tá com trauma de ir ao colégio, e você tem medo de ir para o colégio.

As palavras utilizadas carregam em si um significado e não puderam ser substituídas por uma única palavra, conforme os postulados de Vygotsky (1991[1987]) acerca do desenvolvimento dos conceitos. Essa capacidade de expressão relatada pelos sujeitos ao fazer essas escolhas mostrou um domínio semântico bem constituído e em desenvolvimento, pois perceberam as relaçôes internas com outras palavras, com a frase, com o texto, com a intenção de comunicar-se por escrito com expressividade.

O grupo I se destacou quanto à consciência na escolha das palavras com relação à intenção social da escrita, expondo nos relatos o motivo paralelo de suas frases. Esses motivos foram explicitados como fatos marcantes e manifestos por palavras que expressaram sentimentos e emoções e a resolução de um conflito.

O grupo II mostrou uma vaga percepção da intenção social de seus textos e dos desvios quanto ao uso dos sentidos das palavras no contexto de interação, mas Marcos as empregou com objetivo de explicitar seus pensamentos para melhor entendimento do outro.

\section{Categoria 4 - efeitos}

O objetivo foi o de verificar se os sujeitos obtiveram consciência do resultado da escolha de suas palavras no outro. A criança que percebeu as consequiências do uso no leitor revelou consciência metalingüística mais avançada, pois entendeu que suas palavras despertam uma multiplicidade de interpretação acerca de suas idéias, indicam sua forma de pensar e regulam os sentidos que o interlocutor assume.

A consciência de que vários pensamentos mobilizam as escolhas pode facilitar a realização da escritura de um texto, isto porque o motivo gerador destas escolhas deve estar muito claro e definido ao escrever um texto com objetivo de comunicarse. Essa reflexão supõe uma criação de significados surgidos no momento da 
concepção do texto, mas, que durante a interlocução podem ser (re)significados após a leitura compartilhada com a participação do outro.

O grupo I apresentou forte consciência da multiplicidade de interpretação acerca de suas frases, percebendo a aceitação de suas idéias pelo outro. Lena, Cléa, Jane, Bia e Pedro entenderam que suas idéias foram aceitas e compreendidas pelo outro, por se tratar de vivências relatadas e de assuntos compartilhados no mesmo plano sócio-ideológico (Bakhtin, 1997). A discordância das idéias, portanto, não foi considerada por eles, pois os textos produzidos atendiam ao contexto situacional.

\section{P: E as outras pessoas que poderão ler, você acha que poderão entender?}

Lena: Acho. Porque eu fiz bem explicado.

Cléa: Assim, se a pessoa ler assim que meio de uma forma que ela compreenda, depende do jeito que a pessoa compreender, se ela compreender de um jeito ela vai entender de um jeito e se ela compreender de outro jeito ela ... É, vai depender da pessoa.:

Marcos: Porque tá bem, tá fácil de entender, não tá melhor história do mundo, assim em partes, né?! Mas tá fácil de entender.

Marcos manifestou em quase todas as categorias (contexto, intenção social, efeitos) habilidade na escolha das palavras, isto é, consciência pragmática, diferenciando-se do seu grupo I quanto ao desempenho nas tarefas propostas.

\section{CONSIDERAÇÕES FINAIS}

Constatou-se que os integrantes do Grupo II, de menor consciência metalingüística fonológica quanto a erros ortográficos, em sua maioria, apresentou baixo nível de consciência metalingüística pragmática, dos aspectos importantes da concepção de um texto. O objetivo de comunicar-se através da escrita foi pouco observado nos relatos de explicitação desses alunos. Os relatos verbais não se apoiaram nos textos, mas nos fatos vivenciados, os quais foram recontados por eles no momento da interação com a pesquisadora, a fim de clarear as palavras não escritas. Os textos apresentaram-se lacunares quanto ao uso apropriado das palavras para provocar efeitos no outro, revelando pouca preocupação com o outro real ou imaginário e pouco uso de marcadores lingüísticos.

Certo distanciamento com o texto produzido e um menor envolvimento com a proposta foram observados durante a interlocução com esses alunos do Grupo II. As perguntas, muitas vezes, foram repetidas e reformuladas para que pudessem compreender o que estava sendo investigado em suas produçôes.

Como não foi o foco investigar a relação entre consciência metalingüística 
fonológica e a consciência metalingüística pragmática, mas sim verificar como os sujeitos de níveis diversificados de consciência metalingüística escolhem as palavras para dar o sentido pretendido em suas produçōes escritas, pontua-se a necessidade de estudos posteriores para elucidar tal relação e levantar os possíveis fatores que interferem no envolvimento da produção dos sujeitos com baixo nível de consciência fonológica.

Importante ressaltar que a consciência metalingüística pragmática por ser uma competência comunicativa, pode ser desenvolvida no curso dos vários anos de escolaridade, sendo construída pouco a pouco por meio das interações. Ao considerá-la fundamental para o desenvolvimento do sujeito histórico-cultural em seu processo de interação com o outro e com as demandas contextuais do meio em que está inserido, partiu-se do princípio que há um percurso de constituição dos recursos lingüísticos para operar com a língua, sendo a linguagem oral (fala) e o pensamento articulados com a consciência metalingüística pragmática na dialogia dos textos.

Embora a consciência metalingüística pragmática seja um resultado de aprendizagens escolares, as tarefas que enfocam o seu uso requerem um nível mais abstrato, elaborado e controlado do pensamento, mas foi verificado que nem sempre está presente nos sujeitos de 10 a 11 anos de idade. Entretanto, há necessidade de despertar essa consciência o que demanda um certo conhecimento da linguagem quanto aos conceitos, classificações, etc. (Correa, 2004), uma vez que a linguagem integra a estrutura dos processos cognitivos, além de agir como meio de regular e mediar a atividade psíquica humana, postulado por Vygotsky (1991[1987]).

As operações psíquicas manifestadas nas atividades verbais dos alunos incidiram sobre os aspectos contextuais, estruturais, usuais e interativos, conscientes ou não, e que tomaram a língua como objeto, a partir da mediação. Um momento de desenvolvimento psicológico observado durante as entrevistas de explicitação, foi o da interlocução com a pesquisadora, pois à medida que as crianças foram reconhecendo por meio da mediação os sentidos produzidos por suas escolhas, conhecimento e compreensão de aspectos intrínsecos simbolizados pelas palavras escritas estiveram presentes na dialogia dos textos.

Pode-se dizer que a participação do outro real ou imaginário, em maior ou menor grau, em todos os momentos (antes, durante e após a produção dos textos) se fez presente nas quatro categorias destacadas, direcionando, selecionando e organizando as palavras para produzir o efeito desejado no outro, embora mesmo assim tenham ocorrido os desvios de efeito. Estes indicaram a necessidade de valorizar os momentos interativos para que se desperte nos sujeitos a consciência do uso das palavras nos contextos. Observou-se que essa consciência possibilita a aproximação do uso das palavras ao efeito pretendido. Quando isso não era planejado conscientemente pelos sujeitos, as produções escritas apresentavam-se 
lacunares, com maiores espaços para que ocorressem os desvios de entendimento do leitor.

Os sujeitos que revelaram uma forte percepção dos significados implícitos e explícitos, sentidos que estão dentro e fora dos enunciados, também apresentaram forte percepção ao compartilhar estes significados por meio de marcadores lingüísticos, o que indicou uma habilidade na escolha das palavras que ia ao encontro do objetivo, do uso dessas palavras no contexto, o que confirmou ser a consciência pragmática desenvolvida através da relação com o outro e com o meio social, ou seja, em atividades de ensino por meio da mediação, por meio da leitura reflexiva, no embate com o pensamento alheio e com objetivo da ação de escrever para comunicar-se.

A leitura, mesmo não sendo o foco desse trabalho, esteve presente no momento da escritura dos textos e nas entrevistas de explicitação. A escrita, apoiada nessa leitura reflexiva, foi resultado dessa reflexividade durante a produção e contribuiu para o reconhecimento dos sentidos produzidos no encontro com o outro. Tratase de leitura do próprio sujeito escrevente acerca de suas escolhas (leitura interna), e a leitura do outro, que é reflexo do uso dessas palavras no contexto da produção. A reflexão impulsionada pela dialogicidade, na situação de interação, mobilizou funçôes psíquicas, tais como, reconhecer, identificar, analisar, compreender e avaliar as palavras no texto e seus efeitos no outro. Assim, confirmou-se também a necessidade da leitura ao permear toda ação do ato de escrever. Escrever, então, com consciência pragmática, parece ter uma relação com a leitura. Os significados e os sentidos das palavras numa produção escrita parecem se originar da leitura de quem escreve e de quem lê, ao tomar o texto como objeto de compreensão num determinado contexto. Gombert \& Gaux (1999) afirmam que há uma tendência em mostrar que a consciência sintática influencia a leitura, e se desenvolvem em interação e, de fato, ao longo do desenvolvimento ocorrem mudanças significativas na apropriação da língua escrita e no uso da linguagem. A tomada de consciência a partir da interação é a força propulsora principal de todo o desenvolvimento (Rossi, 1998), nessa evolução. Tanto quem escreve quanto quem lê, ora um, ora outro, faz uma leitura de si mesmo e de suas experiências na cultura, cria textos na dialogia, estabelecendo uma troca contínua.

Desse modo, durante as investigações sobre o processo de escrever, a leitura reflexiva da escrita compareceu junto à consciência de estar e viver em sociedade.

A investigação foi capaz de captar uma especificidade das crianças na constituição e no uso dos recursos lingüísticos, dos conceitos científicos, tais como regras e estruturas da língua. Perceberam-se indícios de uma relação que se estabelece entre o domínio dos recursos lingüísticos e a habilidade de escrever com consciência pragmática quanto à relação estabelecida com a leitura, de maior ou menor maturidade. Os sujeitos com maior domínio de recursos lingüísticos apresentaram maior percepção dos aspectos envolvidos na concepção de um texto 
(contexto, uso, intenção social, efeitos), são leitores mais maduros, refletem a realidade com consciência.

A diferença marcante de Marcos quanto aos demais integrantes do Grupo II merece uma reflexão quanto à variação. Ele chegara á escola, transferido do Rio Grande do Sul, há poucos meses. Os demais já estudavam na escola desde as séries iniciais. Como este estudo não visou às práticas de ensino, mas a apropriação das crianças dos recursos de uso da língua/linguagem para a escrita, seria importante em estudos mais aprofundados examinar essa influência na produção de sentidos de um texto. Outra possibilidade de investigação futura seriam os desdobramentos da habilidade metalingüística pragmática na compreensão de diferentes gêneros textuais e sua influência no desenvolvimento de conhecimentos científicos em diversas disciplinas.

Pensar na habilidade metalingüística pragmática como essencial ao desenvolvimento de competências para a escrita, oferece uma contribuição aos Parâmetros Curriculares Nacionais (Ministério da Educação, 1998; PCN - Língua Portuguesa, p. 38) no sentido de destacarem a necessidade de os professores de todas as disciplinas se envolverem com mediações que possibilitem o desenvolvimento da consciência metalingüística pragmática no Ensino Fundamental, já que esta apenas é referenciada no documento como afeita ao ensino da Língua Portuguesa.

A escola interfere com o desenvolvimento do aluno, então, não se pode deixar de considerar que ele está no mundo em constante socialização, num movimento dinâmico de construção de conhecimento, de troca, de tomada de consciência de seu próprio processo de aprender. E é a interlocução propiciada no encontro com o outro que desperta e desenvolve essa consciência.

A consciência do erro foi um aspecto que se erigiu como pano de fundo deste estudo e abre perspectivas para que se investiguem como o sujeito pode encarar o seu erro como natural e saudável no momento de escrever, ou como algo que o reporta a incômodos vividos em situações semelhantes de escrita. Neste caso, parece não haver disponibilidade interna do sujeito, no momento, para aceitar o erro e transformá-lo para chegar às intençōes da comunicação.

Os momentos dialógicos de explicitação do texto escrito evidenciaram a facilidade daqueles com maior nível de consciência pragmática em lidar com o erro, revelando aceitação das idéias dos outros e flexibilidade quanto à possibilidade de alterar o que haviam escrito para atender às demandas da comunicação. Entretanto, Marcos, mesmo não apresentando níveis de consciência fonológica compatível com o grupo I, revelou uma estratégia confortável ao lidar com os possíveis erros de sua produção escrita. Fez pouco uso da borracha durante o processo de escrever e esteve seguro na interlocução. $O$ que se percebeu foram indícios de assumir o erro sem tolher, engessar ou mesmo paralisar o ato de escrever para o outro. O estudo sugeriu, portanto, formas diferenciadas na percepção das falhas na 
escrita por parte das crianças e, por conseguinte, dos modos de ensino do próprio conceito de escrita.

Observou-se que por meio do texto produzido pelos alunos pode deflagrar conhecimento da dimensão das palavras nos contextos para entendimento do outro leitor, fazendo com que o sujeito que o escreveu entre em contato com seu próprio pensamento e os caminhos que o levaram a escolher as palavras. Essa atividade psíquica é primordial para a aprendizagem de todos os conteúdos escolares.

Pareceu ainda que as produções escritas, para as crianças, são entendidas como "produtos finais", uma vez que não se observou nelas a necessidade de revisar o que escreveram. Assim, é importante envolvê-las na atividade de produção escrita como algo processual e auxiliá-las a compreender que um texto é o início de um outro duplo produto, o da consciência de si, mediatizado tanto pelos aspectos cognitivos quanto afetivos. Trata-se de considerar os textos como "espaços" de aprendizagem, pautados na dialogicidade, na reflexão sobre a própria língua/ linguagem, surgida nas interações, de modo a buscar compreender o outro e fazerse compreender em situações de diálogo (Geraldi,1997).

Nas entrevistas de explicitação de ambos os grupos, os alunos recorreram aos conhecimentos diversos para produzir suas narrativas, conhecimentos estes que permitiram a reflexão do seu próprio processo de conhecimento. A construção de sentidos entrou em jogo durante a reflexão dos textos em sua concepção e em sua análise posterior. Por esse motivo, o texto produzido deve ser reconhecido como porta de entrada para se compreender os caminhos do pensamento ao articular conhecimento e consciência. Esse processo é fundamental para o desenvolvimento da consciência metalingüística pragmática.

Por intermédio da prática de reflexão acerca das próprias produções escritas, os sujeitos podem pensar o texto como "produtor de sentidos" compartilhados e negociados com o outro. A partir do contato com suas próprias palavras e das palavras dos outros, os sujeitos revelaram um movimento dinâmico, contínuo, que é modificado no curso das interações e que lhes possibilitaram a compreensão de seus próprios processos mentais, tornando-se também conscientes de si próprios e de seu processo de aprender.

\section{REFERÊNCIAS}

Albuquerque, E. B. 1994. O desenvolvimento da consciência metalingüística de texto e sua relação com a produção. Dissertação de Mestrado em Psicologia, UFPE, Recife.

Albuquerque, E. B. e Spinillo, A. 1997. "O conhecimento de crianças sobre diferentes tipos de textos”, em Psicologia: Teoria e Pesquisa. 13 (3), pp: 329-338. 
Bachman, L. F. 1991. "What does language testing have to offer?" Em TESOL, 25 (4), pp: 671-701.

Bachman, L. F. e Clark, J. L. D. 1987. "The measurement of foreign/second language proficiency”, em Annals of the American Academy of Political and Social Science, 490, pp: 20-33.

Bakhtin, M. 1997 [1929]. Estética da criação verbal. Trad: Maria Ermantina Galvão G. Pereira. São Paulo: Martins Fontes.

Bakhtin, M. 1997. Marxismo e Filosofia da Linguagem. São Paulo: Hucitec.

Barrera, S. D. e Maluf, M.R. 2003. "Consciência metalingüística e alfabetização: Um estudo com crianças da primeira série do ensino fundamental”, em Psicologia: Reflexão e Crítica, 16, pp: 1-19.

Bialystok, E. 1993. "Metalinguistic awareness: The development of children's representations of language", em C. Pratt y A. F. Garton (Orgs.) Sistems of representation in children: Develoment and use. New York: Wiley, pp: 211-233.

Borges Dias, M. G. B. 2000. "Raciocínio Lógico, Experiência Escolar e Leitura com Compreensão”, em Psicologia: Teoria e Pesquisa, 16 (1), pp: 55-62.

Cagliari, L. C. 1997. Alfabetização e Lingüistica. São Paulo: Scipione.

Cardoso, J. C. 2000. "Processo de produção textual: o olhar da criança", em III Conferência de Pesquisa Sócio-cultural, Campinas, São Paulo, Brasil.

Carraher, T. N. 1985. "Explorações sobre o desenvolvimento da competência em ortografia em Português”, em Psicologia: Teoria e Pesquisa, 1 (3), pp: 269-285.

Chomsky, N. 1973. Linguagem e Pensamento. Petrópolis: Vozes.

Cielo, C. A. 1998. A sensibilidade fonológica e o início da aprendizagem da leitura. Porto Alegre: Letras de Hoje.

Colaço, V. F. R. 2001. "Interações em sala de aula: Um estudo da atividade discursiva de crianças em séries iniciais”. Tese de doutorado em educação não-publicada. Universidade Federal de Rio Grande do Sul, Porto Alegre, RS.

Correa, J. 2004. "A avaliação da consciência sintática na criança: uma análise metodológica", em Psicologia: Teoria e pesquisa, 20 (1), pp: 60-75.

Crystal, D. 1985. A dictionary of linguistics and phonetics. Oxford: Blackwell. Geraldi, J. W. 1997. Portos de Passagem. São Paulo, SP: Martins Fontes.

Golbert, C. S. 1988. A evolução psicolinguistica e suas implicações na alfabetização. Porto Alegre: Artes Médicas.

Gombert, J. E. 1992. Metalinguistc development. London: Harverster - Wheatsheaf.

Gombert, J. E. 1993. "Metacognition, metalanguage and metapragmatics", em International Journal of Psychology, 28 (5), pp: 571-580.

Gombert, J. E. 2003. "Atividades metalinguísticas e aprendizagem da leitura”, em M. R. Maluf (org.) Metalinguagem e aquisição da escrita: Contribuiçōes da pesquisa para a prática da alfabetização. São Paulo: Casa do Psicólogo.

Gombert, J.E. e Colé, P. 2000. "Activites metalinguistiques, lecture et illettrisme”, em M. Kail y M. Fayol (Orgs.) L'acquisition du language vol. 2. Paris: PUF, pp: 117-150. 
Gombert, J. E. e Gaux, C. 1999. "Implicit and explicit syntactic knowledge and reading in pre-adolescents”, em British Journal of Developmental Psychology, 17, pp: $169-188$.

Guimarães, S. R. K. 2003. “Dificuldades no desenvolvimento da lectoescrita: O papel das habilidades metalinguísticas”, em Psicologia: Teoria e Pesquisa, 19, pp: 33-45.

Hymes, D. H. 1979. "On communicative competence”, em Brumfit, C. J. y Johnson, K. The Communicative Approach to Language Teaching. Oxford: Oxford University Press.

Igoa, M. J. 2003. "El mundo en la mente: Metaconciencia, lenguaje y control en la psicología cognitiva”, em Anuario de Psicologia, 34 (4), pp: 449-503.

Jiménez, J. E. e Venegas, E. 2004. "Defining Phonological Awareness and Its Relationship to Reading Skills in Low-Literacy Adults", em Journal of Educational Psychology, 96 (4), pp: 798-810.

Maluf, M. R. e Barrera, S. D. 1997. "Consciência fonológica e linguagem escrita em pré-escolares", em Psicologia: Reflexão e crítica, 10, pp: 125-145.

Martins, C. C. 1991. "A consciência fonológica e aprendizagem inicial da leitura e da escrita”, em Cadernos de Pesquisa, 76, pp: 41-49.

Ministério da Educação. 1998. Parâmetros Curriculares Nacionais - $5^{a}$ a $8^{a}$ séries. Brasília: MEC/SEF.

Ministério da Educação. 2004. Resultados do SAEB 2003. Relatório, Brasília/DF.

Rego, L. L. B. 1993. "O papel da consciência sintática na aquisição da língua escrita”, em Temas em Psicologia, 1, pp: 79-87.

Rego, L. L. B. 1995. "Diferenças individuais na aprendizagem inicial da leitura: Papel desempenhado por fatores metalingüísticos”, em Psicologia: Teoria e Pesquisa, 11, pp: 51-60.

Rego, L. L. Be Buarque, L. L. 1997. "Consciência Sintática, consciência fonológica e aquisição de regras ortográficas", em Psicologia: Reflexão e Crítica. 10 (2), pp: 199-217.

Rossi, T. M. F. 1998. Desenvolvimento de conceitos: a subversão do simples e do concreto. Brasília: UNB, Tese de Doutorado em Psicologia.

Spinillo, A.G. e Simões, P. U. 2003. "O Desenvolvimento da Consciência Metatextual em crianças: Questōes Conceituais, Metodológicas Resultados de Pesquisas”, em Psicologia: Reflexão e Critica, 16 (3), pp: 537-546.

Yavas, F. 1998. "Habilidades metalingüísticas na criança: Uma visão geral”, em Cadernos de Estudos Lingüisticos, 14, pp: 39-51.

Vygotsky, L.S. 1991[1987]. Pensamento e Linguagem. (Trad: Jeferson Luiz Camargo). São Paulo: Martins Fontes. (Originalmente publicado em 1987.).

Zorzi, J. L. 1998. Aprender a escrever: A apropriação do sistema ortográfico. Porto Alegre: Artes Médicas. 
